\title{
The Impact of Natural Disasters on Domestic Violence: An Analysis of Reports of Simple Assault in Florida (1999-2007)
}

\author{
Sera Gearhart, Maria Perez-Patron, $\mathrm{PhD}^{2}$, Tracy Anne Hammond, PhD, ${ }^{3}$ Daniel W. Goldberg, PhD, \\ Andrew Klein, $\mathrm{PhD}^{4}$ and Jennifer A. Horney, $\mathrm{PhD}, \mathrm{MPH}^{2}$
}

\begin{abstract}
Natural disasters are increasing in frequency and severity worldwide. Associations between individual-level vulnerability to natural disasters and social stratification have been widely demonstrated in the published literature, with excess negative impacts disproportionately affecting women, ethnic and racial minorities, and the elderly. Specifically, several studies have demonstrated a positive relationship between exposure to natural disasters or other extreme events and rates of interpersonal violence (IPV). People experiencing IPV in the postdisaster period may face unique barriers, including loss of access to safe housing and a need to remain with family to qualify for or obtain financial assistance and other types of disaster aid. To assess the potential association between exposure to natural disasters and reports of IPV, the authors used data compiled by the Federal Emergency Management Agency and the Florida Department of Law Enforcement. The Difference in Differences analysis included 819,684 reported assaults in 67 Florida counties over a 9-year period (1999-2007). Longerlasting exposure to natural disaster (>199 days of major declared disaster) was associated with an increase in reports of simple assault in Florida counties. Longer-lasting exposure to disaster among Florida residents increased the expected number of assaults at the county level by approximately 78 per year. Domestic violence in the disaster recovery context carries potentially unique implications due to limited safe housing and loss of community networks. As the frequency and severity of disasters increase globally, disaster relief programs should provide support within this context of increased IPV.
\end{abstract}

Keywords: intimate partner violence, natural disasters, hurricanes, difference in differences, Florida

\section{Introduction}

$\mathbf{N}$ ATURAL DISASTERS ARE increasing in frequency and severity worldwide (Leaning and Guha-Sapir 2013). Although definitions of disaster vary, most research describes a disaster as an acute incident that disrupts normal behaviors in a negative way, which may include extreme social failure and loss of life (Perry 2007). However, the negative impacts of natural disasters are not limited to physical and economic losses. Numerous psychological consequences, including increased levels of depression and anxiety, have been reported not only for immediate victims of disasters (Briere and Elliott 2000) but also for public health and public safety workers aiding in disaster relief (Benedek et al. 2007). Past research has also linked exposure to natural disasters with increased suicide risk (Petro- vich et al. 2001) and posttraumatic stress disorder (Norris et al. 2002). As natural disasters are associated with a breakdown in normal functioning social relationships, these adverse mental health effects may be exacerbated by a loss of preexisting social support (Kanaisty and Norris 1995).

While increases in the incidence of negative physical and mental health impacts from natural disasters may, in part, be attributed to better and more accurate forecasting and reporting, recent hazards and disasters research provides evidence that the prevalence and severity of natural hazards such as flooding and severe storms is increasing (Loftis 2015; Wisner et al. 2004). Between 1994 and 2013, natural disasters claimed an average of nearly 68,000 lives per year, affecting nearly 218 million people over the entire period (Centre for Research on the Epidemiology of Disasters 2015). In 2016, natural disasters caused more than $\$ 175$

\footnotetext{
${ }^{1}$ Department of Public Policy, University of Redlands, Redlands, California.

Departments of ${ }^{2}$ Epidemiology and Biostatistics, ${ }^{3}$ Computer Science and Engineering, and ${ }^{4}$ Geography, Texas A\&M University, College Station, Texas.
} 
billion in overall economic loss, while only a fraction of those losses were insured (Riley 2017). The economic costs and other impacts of natural disasters will continue to grow over time as populations and economic development in vulnerable areas continue to increase (Riebeek 2005).

At the individual level, vulnerability to the impacts of natural disasters has been shown to be strongly associated with various aspects of social stratification. Therefore, vulnerability to the impacts of natural disasters is not only a function of biophysical hazard exposure but also the social and community vulnerability context (Cutter et al. 2000; Peacock et al. 1997; Wisner et al. 2004). Overall, women, children, the elderly, members of racial and ethnic minority group, and persons living in poverty are differentially and negatively impacted by natural disasters (Bourque et al. 2007). For example, one study of flooding in Pakistan found that the adverse effects of flooding more heavily impacted poorer and more disenfranchised segments of the population (Mustafa 1998). Case study data have also been supported by larger studies. In a review of the impacts of natural disasters, Striessnig and Loichinger (2015) found that higher levels of education were inversely associated with disasterrelated fatalities. Disasters appear to exacerbate preexisting social inequalities, disproportionately victimizing women, especially in developing nations (Enarson and Fordham 2001; Enarson et al. 2007; Hines 2007; Neumayer and Plümper 2007; Wiest et al. 1994;) and racial and ethnic minorities (Bolin 2007).

Multiple studies have found a relationship between natural disasters and increased rates of interpersonal violence (IPV) (Chew and Ramdas 2005; Lewin 2001; Parkinson and Zara 2013;), which in some cases persists well beyond the immediate aftermath of an event (Fisher 2010). IPV is generally understood as violent behavior within the home, especially involving spousal or romantic relationships. According to the National Institute of Justice, IPV occurs more frequently in disadvantaged neighborhoods, especially among households that experience significant financial strain (Benson and Fox 2004). More than half of all homicides with female victims have been found to be related in some way to a current or past intimate partner (Petrosky 2017).

The natural disaster context may compound preexisting risk factors for domestic violence by increasing feelings of helplessness and giving prominence to feelings of loss of control over the well-being and protection of one's family (Coontz 1992). For example, following the 2009 "Black Saturday" bushfires in Australia, qualitative interviews and anecdotal evidence revealed an increase in IPV among those families that were affected (Parkinson and Zara 2013). Research after Hurricane Andrew, a Category 5 hurricane that made landfall in South Florida in 1992, found that spousal abuse calls to Miami's helpline increased by 50 percent postdisaster. More than one-third of calls reporting abuse stated that someone living in the home had recently been stressed to the point of losing physical or verbal control (Morrow 1997).

People experiencing IPV during the postdisaster recovery period may face unique barriers to receiving assistance or escaping their situation. While research and best practices from disaster recovery aim to provide insights that will improve the pace and quality of disaster recovery and mitigate future losses through resilience building, there is fre- quently an emphasis on the importance of the family unit in times of great duress. For example, to reduce the risk of mental health sequelae, service providers advise keeping kinship networks and family units intact to the extent possible (Norris et al. 2002). However, the safety of the family unit itself is an issue that has largely not been addressed by relief organizations, which are often working under very difficult conditions to meet the immediate physical and mental health needs of a large number of people. For example, interviews with service providers following Hurricane Andrew indicated that it was often the first family member to submit an application for each home address who would ultimately receive direct aid, with the expectation that this aid would be shared equitably within a family unit (Enarson and Morrow 1997). In providing aid, crisis workers may also rely on traditional gender roles, limiting the autonomy of women within the family (Enarson and Morrow 1997). Qualitative research after Hurricane Andrew highlighted the inability of agencies to provide adequate aid to families that deviated from the traditional nuclear family structure, with some women citing judgmental and accusatory attitudes of caseworkers (Morrow 1997). Domestic violence shelter facilities, already limited during nondisaster periods, are themselves as likely to be damaged as any other building in a community impacted by a disaster, which may reduce capacity. Postdisaster living arrangements, such as shelters and temporary housing for evacuees, may exacerbate preexisting barriers to seeking help. After Hurricane Katrina, a shelter system that was designed to provide safe housing in the very short term was stressed by the displacement of Gulf Coast residents across the United States for a period of many months (Meth 2001). The inadequacies of the shelter system meant that IPV victims impacted by Hurricane Katrina were more likely to remain with an abusive partner, or even return to an abusive partner out of desperation (Jenkins and Phillips 2008).

The impact of natural disasters on rates of IPV remains quantitatively elusive for several reasons. IPV remains largely underreported, and data collection in areas devastated by natural disaster is understandably methodologically challenging. The disaster context may exacerbate existing barriers to reporting, and even contribute to community-wide indifference toward the issue, as victims are encouraged to forgive their abusers, or are accused of being inconsiderate or overreacting (Parkinson and Zara 2013). The goal of this analysis is to provide a foundation for defining the impact of natural disasters on rates of IPV to inform future interventions and policy.

\section{Materials and Methods}

\section{Data sources}

The President of the United States can declare a major disaster under the authority provided by the Stafford Act in response to a request from the Governor of an affected state (Federal Emergency Management Agency [FEMA] 2016). County-level data on major disasters declared in the State of Florida between 1999 and 2007 were compiled from FEMA (FEMA 2014). County-level data on police reports of simple assault during the same time period were obtained from the Florida Department of Law Enforcement (Florida Department of Law Enforcement, 
Table 1. Number and Type of Assaults BY Year, Florida, 1999-2007 $(N=819,684)$

\begin{tabular}{cr}
\hline Year & Number \\
\hline 1999 & 94,369 \\
2000 & 93,296 \\
2001 & 92,893 \\
2002 & 91,299 \\
2003 & 90,781 \\
2004 & 90,079 \\
2005 & 90,455 \\
2006 & 88,110 \\
2007 & 88,402 \\
Total & 819,684 \\
&
\end{tabular}

n.d.). County-level unemployment statistics were obtained from the Bureau of Labor Statistics (United States Department of Labor, Bureau of Labor Statistics, n.d.). The three datasets were merged using County and State Federal Information Processing Standards codes.

\section{Data analysis}

Difference-in-differences (DID) models can be used to highlight changes between treated and untreated groups in longitudinal studies where potential confounders are time invariant. To apply the DID method, the authors dichotomized the number of days in which a major disaster was declared in each county in the State of Florida, with counties with more than 199 days of major disaster declaration per year designated as treated and counties with 199 days or less of major disaster declaration per year designated as untreated. One hundred and ninety-nine days were selected as the treatment cut point because many Florida counties experienced at least 150 days of major disaster declaration in 2004. Only counties impacted by all four hurricanesCharley, Frances, Ivan, and Jeanne, as well as tropical storm Bonnie-had more than 199 days of major disaster declaration. The authors assessed this variable and found it to be highly correlated with other measures of disaster exposure, such as the total amount of individual assistance and housing assistance dollars approved per capita.

Using natural disaster treatment as defined above, the authors attempted to quantify the association between exposure to more than 199 days of major disaster declaration during the severe hurricane season of 2004 and reports of simple assault, defined as an attempt to cause physical harm to someone and including fear of battery or reasonable apprehension that a crime is imminent if no physical harm occurs. Based on the review of literature and subject matter expertise, they hypothesized that more days of major disaster declaration would be positively associated with reports of simple assault at the county level. The authors controlled for changes in the unemployment rate over this period, a factor that has been shown to affect rates of IPV, as well as for county population characteristics and timespecific effects (Equation 1).

\section{Equation 1. Difference-in-Differences Model}

$$
\begin{aligned}
Y= & B_{0}+B_{1} X+B_{2} Z+C_{1}+C_{2}+C_{3}+\ldots C_{67} \\
& +T_{1}+T_{2}+T_{3}+\ldots T_{9}
\end{aligned}
$$

$Y$ is the number of simple assaults reported in a county in a single year, $B_{O}$ is the y-intercept of the model, and $B_{1}$ is the coefficient of interest on $X$-an interactive variable capturing possible differences between the treatment and control

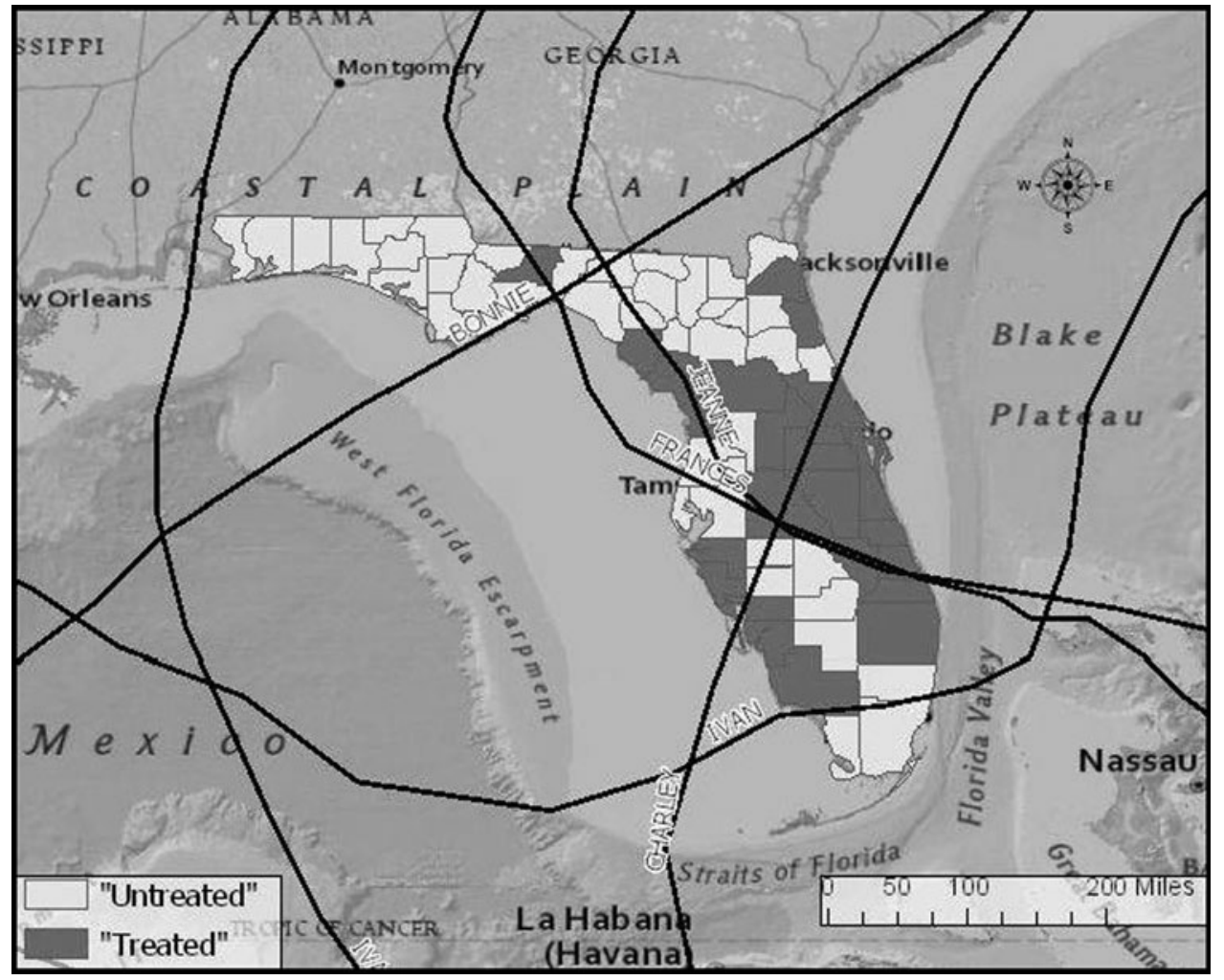

FIG. 1. Tracks of Hurricanes Charley, Frances, Ivan, and Jeanne and Tropical Storm Bonnie and County-Level Exposure to $>199$ days of Major Disaster Declaration, Florida, 2004. 
FIG. 2. Treated and Untreated Groups, Florida, (1999-2007).
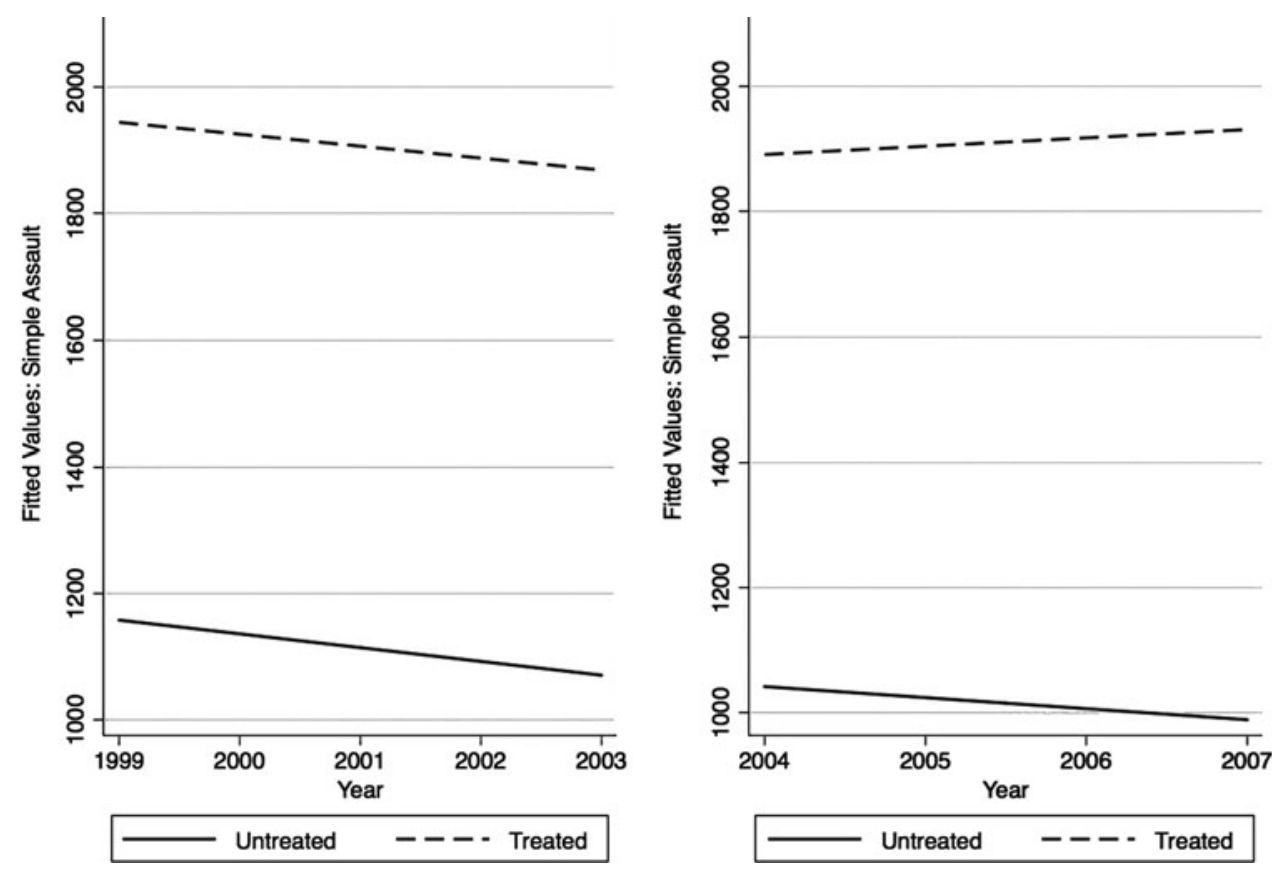

groups-equaling one for those counties that qualified as treated in the years following 2004, inclusive. $B_{2}$ is the coefficient of interest on $Z$, a variable controlling for changes in the unemployment rate in counties across the time period studied. $C_{1}+C_{2}+C_{3}+\ldots C_{67}$ are controls for county-level characteristics of the 67 Florida counties, and $T_{1}+T_{2}+T_{3}+\ldots T_{9}$ are controls for year-specific characteristics where $T_{1}$ is 1999 and $T_{9}$ is 2007 .

All analyses were conducted using Stata v. 14 (College Station, TX). This research was reviewed by the Texas A\&M Institutional Review Board and determined to be exempt (IRB 2017-0526).

\section{Results}

\section{Simple assaults}

Between 1999 and 2007, there were a total of 819,684 reports of simple assault in 67 Florida Counties (Table 1).

\section{Disaster declarations}

Major disaster declarations were in place for at least 200 days in 24 of 67 Florida counties (36\%) during 2004, when four separate hurricanes, Charley, Frances, Ivan, and Jeanne, and one severe tropical storm, Bonnie, impacted the State of Florida between August 12 and September 26 (Fig. 1).

\section{DID model}

Beyond the typical assumptions underlying statistical models, the validity of a DID model requires additional assumptions related to parallel trends in county attributes. Trends within both treated ( $>199$ days of major disaster declaration) and untreated ( $\leq 199$ days of major disaster declaration) counties must be comparable within the first time period for valid inferences to be drawn about the second time period without residual confounding by factors that change differently over time. In this case, trends in the treated and untreated groups (shown in solid and dashed lines, respectively) are parallel for the initial time period (1999-2003), but diverge during the postdisaster period (2004-2007) when fitted values of simple assault are plotted against time (Fig. 2). Counties in both the treated and untreated groups experienced comparable decreases in reports of simple assault in the years leading up to 2004. However, following a year of intense hurricanes and tropical storms in 2004, there was an increase in simple assault in the treated group over the subsequent 4 years. The change in the number of simple assaults during the postdisaster period captures the hurricane effect.

The final adjusted DID model suggested a statistically significant association between exposure to 200 or more days of major disaster declaration and the number of simple assaults reported in Florida counties over the 9-year period from 1999 to 2007. Exposure to a disaster declaration for 200 or more days was associated with an increase of

Table 2. Summary Results from Difference in Differences Model

\begin{tabular}{|c|c|c|c|c|}
\hline & Model coefficients & Standard error & $P>|t|$ & $95 \%$ Confidence interval \\
\hline Duration interaction & 78.49 & 35.75 & 0.03 & 8.26-148.72 \\
\hline Constant & 1260.26 & 84.10 & 0.00 & $1095.05-1425.48$ \\
\hline Unemployment rate & 8.79 & 12.12 & 0.47 & -15.02 to 32.60 \\
\hline
\end{tabular}


approximately 78 simple assaults annually, controlling for unemployment $(p=0.03)$ (Table 2).

\section{Discussion}

The differential impacts of the severe 2004 hurricane season across Florida counties present a unique opportunity to quantify the impacts of disaster on IPV. Using DID methods, this analysis demonstrated that the disruption of normal community function by natural disasters that result in long-term major disaster declarations can have a significant, positive effect on reports of simple assault, controlling for changes in employment status, and county- and timespecific trends. Although existing research has provided qualitative evidence of psychological malaise and the negative impacts such stressors have on families following natural disasters, this analysis provides a first step toward quantifying the magnitude of this issue.

This study has several limitations. First, data are available only on the county level, and thus descriptive power is limited for exploration of the associations between disasters and IPV across classifications of race, ethnicity, class, and type of relationship. However, the usefulness of DID methods in controlling for confounding in ecological analyses has been demonstrated in the disaster literature (Grabich et al. 2015). Second, analysis is limited to the state of Florida, where data on IPV were available, and may not be representative of the impact of natural disasters on IPV across the rest of the United States or globally. Third, 2004 was adverse for all counties in Florida, not only for those that were classified as treated because they were impacted by all four hurricanes and a major tropical storm. It follows that the total difference in reporting may not be fully captured in the analysis provided in this study, as reporting in untreated counties may also have been inflated since some had up to 150 days of exposure to a major disaster declaration. However, this would result in the analysis underestimating the impact of natural disasters on IPV. Although studies exploring the validity of varying classifications of hurricane treatment have found roughly equivalent outcomes across a wide range of classification methods, such as mapping and wind speed analysis (Grabich et al. 2015), the method of assigning counties within a binary of "treated" or "untreated" cannot account for within-county differences in disaster impact. IPV is chronically underreported. It follows that the breakdown in effective communication following natural disasters would further exacerbate this fact, leading to significant underreporting during the timeframe of the event, another potential reason why these results could underestimate the impact of natural disasters on IPV.

Future research should address the above limitations by seeking to perform analyses with enriched individual-level information. Extending the timeframe examined postdisaster, as well as focusing on changes from 1 year to the next post-disaster may offer useful insight as to when interventions are most likely to be effective. In addition, researchers should investigate the differential impact of natural disasters on different types of relationships, as research has found that non-heterosexuals are more likely than heterosexuals to be victims of IPV (Walters et al. 2013).

\section{Conclusion}

Domestic violence in the disaster recovery context carries potentially unique implications due to limited safe housing and loss of community networks. This analysis aims to provide quantitative evidence to policymakers that natural disasters have a significant positive impact on reports of IPV. Disaster relief programs should make an effort to provide adequate support within this context of increased IPV, perhaps through cultivating awareness and acceptability of alternative living arrangements, or improving training of relief workers to provide more nuanced responses to the diverse needs of disaster-impacted communities. As the frequency and severity of disasters increase, and their impacts affect a growing population in disasterprone areas, the physical and mental health consequences of natural disasters will become more widespread. There is a need to expand the collective understanding of IPV to include the postdisaster setting, to better meet the needs of impacted individuals and communities.

\section{Acknowledgment}

The authors would like to thank Kahler Stone, MPH, for assistance with data analysis.

\section{Author Disclosure Statement}

No competing financial interests exist.

\section{References}

Benedek, DM, Fullerton C, Ursano RJ. (2007). First responders: Mental health consequences of natural and human-made disasters for public health and public safety workers. Annu Rev Public Health. 28, 55-68.

Benson ML, Fox GL. (2004). When Violence Hits Home: How Economics and Neighborhoods Play a Role. (National Institute of Justice, U.S. Department of Justice, Rockville, Maryland).

Bolin B. (2007). "Chapter 7: Race, Class, Ethnicity, and Disaster Vulnerability." In Handbook of Disaster Research, 113-129. Handbooks of Sociology and Social Research. H Rodríguez, EL Quarantelli, RR Dynes, eds. (New York: Springer). (Springer Science + Business Media, LLC).

Bourque LB., Siegel JM, Kano M, Wood MM. (2007). "Chapter 6: Morbidity and Mortality Associated with Disasters." In Handbook of Disaster Research, 97-112. Handbooks of Sociology and Social Research. H Rodríguez, EL Quarantelli, RR Dynes, eds. (New York: Springer). (Springer Science + Business Media, LLC).

Briere, J, Elliott D. (2000). Prevalence, characteristics, and long-term sequelae of natural disaster exposure in the general population. $\mathrm{J}$ Trauma Stress. 13, 661-679.

Centre for Research on the Epidemiology of Disasters. 2015. "The Human Cost of Natural Disasters: A Global Perspective." http:// emdat.be/human_cost_natdis. (accessed May 29, 2017).

Chew L, Ramdas KN. (2005). Caught in the Storm: The Impact of Natural Disasters on Women. New York, NY: The Global Fund for Women.

Coontz S. (1992). "The Crisis Reconsidered." in The Way We Never Were: American Families and the Nostalgia Trap. (Hatchette UK, New York, NY) pp. 339-374.

Cutter SL, Mitchell JT, Scott MS. (2000). Revealing the Vulnerability of People and Places: A Case Study of Georgetown County, South Carolina. Ann Assoc Am Geographers. 90, 713-737.

Enarson E, Fordham M. (2001). From women's needs to women's rights in disasters. Environ Hazards. 3, 133-136. 
Enarson E, Fothergill A, Peek L. (2007) "Chapter 8: Gender and disaster: foundations and directions." In Handbook of Disaster Research, 130-146. Handbooks of Sociology and Social Research. H Rodríguez, EL Quarantelli, RR Dynes, eds. (New York: Springer). (Springer Science + Business Media, LLC).

Enarson E, Morrow BH. (1997) "Chapter 7: A Gendered Perception: The Voices of Women." In Hurricane Andrew: Ethnicity, Gender, and the Sociology of Disasters. WG Peacock, BH Morrow, $\mathrm{H}$ Gladwin, eds. (Routledge: London).

Federal Emergency Management Agency. (2014). FEMA Disaster Declarations by Year. www.fema.gov/disasters/grid/year (accessed May 29, 2017).

Federal Emergency Management Agency. (2016). The Disaster Declaration Process. www.fema.gov/disaster-declaration-process (accessed May 29, 2017).

Fisher S. (2010). Violence against women and natural disasters: Findings From Post-Tsunami Sri Lanka. Violence Against Women. 16, 902-918.

Florida Department of Law Enforcement - UCR Domestic Violence. www.fdle.state.fl.us/cms/FSAC/Data-Statistics/UCR-DomesticViolence.aspx (accessed May 29, 2017).

Grabich S, Horney JA, Konrad C, Lobdell D. (2015). Measuring the storm: Methods of quantifying hurricane exposure with pregnancy outcomes. Nat Hazards Rev. 17:06015002.

Hines RI. (2007). Natural Disasters and Gender Inequalities: The 2004 Tsunami and the Case of India. Race Gender Class. 14, 60-68.

Jenkins P, Phillips B. (2008). Battered Women, Catastrophe, and the Context of Safety After Hurricane Katrina. NWSA J, no. 3, New Orleans: A Special Issue on Gender, the Meaning of Place, and the Politics of Displacement. (Fall 2008) 20: 49-68.

Kanaisty K, Norris FH. (1995). Mobilization and deterioration of social support following natural disasters. Curr Dir Psychol Sci. 4, 94-98.

Leaning J, Guha-Sapir D. (2013). Natural disasters, armed conflict, and public health. N Engl J Med. 369, 1836-1842.

Lewin T. Shelters Have Empty Beds; Abused Women Stay Home. The New York Times, October 21, 2001, sec. U.S.

Loftis RL. (2015). National Geographic PUBLISHED November 5, 2015. Half of Weather Disasters Linked to Climate Change. National Geographic News. (National Geographic Society, Washington, DC).

Meth P. (2001). The Shelter Dilemma for Women Experiencing Domestic Violence. Agenda: Empowering Women for Gender Equity 48, no. Globalisation: Challenging Dominant Discourses. pp.113-119. https://doi.org/10.1080/10130950.2001.9675959

Morrow BH. (1997). Chapter 8: Stretching the Bonds: The Families of Andrew. In Hurricane Andrew: Ethnicity, Gender, and the Sociology of Disasters. WG Peacock, BH Morrow, H Gladwin, eds. (Routledge: London).

Mustafa D. (1998). Structural causes of vulnerability to flood Hazard in Pakistan. Econ Geogr. 74, 289-305.

Neumayer E, Plümper T. (2007). The gendered nature of natural disasters: The impact of catastrophic events on the gender gap in life expectancy, 1981-2002. Ann Assoc Am Geographers. 97, 551-566.
Norris FH, Friedman MJ, Watson PJ. (2002). 60,000 Disaster Victims Speak: Part II. summary and implications of the disaster mental health research. Psychiatry. 65, 240-260.

Parkinson D, Zara C. (2013). The hidden disaster: Domestic violence in the aftermath of natural disaster. Aust J Emerg Manage. 28, 28-35.

Peacock WG, Ragsdale AK. (1997). "Chapter 2: Social systems, ecological networks, and disasters: towards a socio-political ecology of disasters." In Hurricane Andrew: Ethnicity, Gender, and the Sociology of Disasters. (Routledge: London).

Perry RW. (2007) "Chapter 1: What Is a Disaster?" In Handbook of Disaster Research, 1-15. Handbooks of Sociology and Social Research. H Rodríguez, EL Quarantelli, RR Dynes, eds. (New York: Springer). (Springer Science + Business Media, LLC).

Petrosky E. (2017). Racial and Ethnic Differences in Homicides of Adult Women and the Role of Intimate Partner Violence-United States, 2003-2014. MMWR. 66:741-746.

Petrovich B, Tiodorovich B, Kocich B, et al. (2001). Influence of socio-economic crisis on epidemiological characteristic of suicide in the region of nis (Southeastern Part of Serbia, Yugoslavia). Eur J Epidemiol. 17, 183-187.

Riebeek H. (2005). The rising cost of natural disasters. NASA Earth Observatory, March 28. Retrieved from https://earthobservatory .nasa.gov/Features/RisingCost/rising_cost4.php, (Accessed January 21, 2009).

Riley C. (2017). Natural Disasters Caused \$175 Billion in Damage in 2016. London, England: CNNMoney.

Striessnig, E, Loichinger E. (2015). Future differential vulnerability to natural disasters by level of education. Vienna Yearbook Popul Res, no. Special Issue on Demographic Differential Vulnerability to Climate-Related Disasters. 13:221-240.

United States Department of Labor, Bureau of Labor Statistics. Local Area Unemployment Statistics. www.bls.gov/lau/\#tables (accessed May 29, 2017).

Walters ML, Chen J, Breiding MJ. The National Intimate Partner and Sexual Violence Survey (NISVS): 2010 Findings on Victimization by Sexual Orientation. Atlanta, GA: National Center for Injury Prevention and Control, Centers for Disease Control and Prevention, 2013.

Wiest RE, Mocellin JSP, Motsisi DT. (1994). The Needs of Women In Disasters and Emergencies. Disaster Research Institute. (University of Manitoba, Winnipeg, Canada).

Wisner B, Blaikie P, Cannon T, Davis I. (2004). At Risk: Natural Hazards, People's Vulnerability and Disasters (2nd edition.). (New York, NY: Routledge).

Address correspondence to: Jennifer A. Horney, PhD, MPH Department of Epidemiology and Biostatistics Texas A\&M University 1266 TAMU

College Station, TX 77843

E-mail: horney@sph.tamhsc.edu 